\title{
28 Research Square \\ Shedding light on microbial dark matter in Shark Bay, Australia
}

Hon Lun Wong

Fraser I. MacLeod

Richard Allen White III

Pieter T. Visscher

Brendan P. Burns

\section{Video Byte}

Keywords: Shark Bay, Australia, microbial dark matter, MDM, microbial mats, ocean, Microbiome

Posted Date: November 12th, 2020

DOl: https://doi.org/10.21203/rs.3.rs-106700/v1

License: (9) This work is licensed under a Creative Commons Attribution 4.0 International License.

Read Full License 


\section{Abstract}

Microbial mats are windows to our past of the earliest ecosystems to evolve on earth, especially those found in Shark Bay, Australia. Here, these lush mats are shedding light into the lives of microbes that are yet to be cultured in the lab, an untapped resource of biological information known as "microbial dark matter". In a new study, researchers reconstructed 115 genomes belonging to members of this microbial dark matter. The researchers detected entirely new microorganisms that may participate in sulfate reduction, microbes capable of fermenting and degrading organic carbon, and microbes with a high capacity for producing hydrogen. Overall, the results suggest that microbial dark matter could play critical roles in nutrient cycling across the planet. Further genomics studies could place novel microorganisms found in microbial mats into their proper ecological and environmental context and offer clues on how to cultivate these microbes in the lab for closer examination. 